\title{
Lipopolysaccharide-binding protein is efficient in biodosimetry during radiotherapy of lung cancer
}

\author{
JUSTYNA CHALUBINSKA-FENDLER ${ }^{1}$, WOJCIECH FENDLER ${ }^{2}$, MICHAL SPYCH $^{1}$, \\ KRYSTYNA WYKA ${ }^{3}$, JOLANTA LUNIEWSKA-BURY ${ }^{4}$ and JACEK FIJUTH ${ }^{1}$ \\ ${ }^{1}$ Department of Radiotherapy, Medical University of Łódź, 93-509 Łódź; Departments of ${ }^{2}$ Biostatistics and \\ Translational Medicine, and ${ }^{3}$ Paediatrics, Oncology, Haematology and Diabetology, Medical University of Łódź,

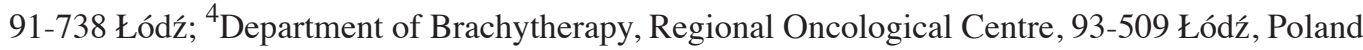

Received April 5, 2016; Accepted June 16, 2016

DOI: $10.3892 /$ br.2016.739

\begin{abstract}
The aim of the present study was to determine if the serum levels of early markers of inflammation, such as interleukin-6 (IL-6), tumor necrosis factor- $\alpha$ (TNF- $\alpha$ ), C-reactive protein (CRP), and lipopolysaccharide-binding protein (LBP) were correlated with the radiation dose received by the pulmonary and mediastinal structures of patients with non-small cell lung cancer (NSCLC). This pilot study included 26 patients with NSCLC who received total radiation doses ranging from 54 to $74 \mathrm{~Gy}$ (2.0 Gy/fraction). Cytokines were measured at baseline by enzyme-linked immunosorbant assay, and following administration of total doses of 20 and $40 \mathrm{~Gy}$. A control group of 26 participants was sampled for comparisons with patient baseline cytokine levels. Only data from the 40-Gy cytokine blood levels of patients with NSCLC were identified to be correlated with histograms of the parameters of each patient's radiotherapy protocol. The IL-6, TNF- $\alpha$ and CRP median baseline levels of the patients with NSCLC were significantly higher than those of the controls (all $\mathrm{P} \leq 0.01$ ). No differences were observed between the LBP levels of the patients and controls [median, 36.34 (25-75\%; 31.35-39.27) vs. $36.92(30.20-44.05) \mu \mathrm{g} / \mathrm{ml}$, respectively; $\mathrm{P}=0.42]$. No significant differences in the levels of the four cytokines between baseline, and at 20 and $40 \mathrm{~Gy}$ were observed [IL-6 ( $\mathrm{P}=0.19)$; TNF- $\alpha(\mathrm{P}=0.68)$; CRP $(\mathrm{P}=0.44)$ and LBP $(\mathrm{P}=0.29)$ ]. LBP was significantly and positively correlated with the mean radiation dose to the lung $(\mathrm{r}=0.409 ; \mathrm{P}=0.038)$, and showed a positive correlation with the percentage of lung volume exposed to at least $20 \mathrm{~Gy}$ of the planned radiation dose $(r=0.3536 ; \mathrm{P}=0.0764)$. CRP levels were positively correlated with the mean radiation dose to the esophagus $(r=0.404 ; \mathrm{P}=0.041)$; however, IL-6,
\end{abstract}

Correspondence to: Dr Justyna Chalubinska-Fendler, Department of Radiotherapy, Medical University of Łódź, 4 Paderewskiego Street, 93-509 Łódź, Poland

E-mail: justyna.chalubinska-fendler@e.umed.lodz.pl

Key words: lipopolysaccharide-binding protein, biodosimetry, radiotherapy, lung cancer, toxicity, adverse effects
TNF- $\alpha$ and CRP were not significantly associated with other lung dosimetry parameters. Thus, LBP levels were correlated with radiation exposure of pulmonary tissues, and LBP may be a marker that warrants further investigation on radiotoxicity in NSCLC patients.

\section{Introduction}

Radiation-induced pulmonary toxicity (RILT) is the most common pulmonary complication in lung cancer patients receiving external beam radiotherapy. Clinical signs and symptoms of RILT occur in 5-20\% of irradiated patients (1). However, the prevalence may be underestimated as, following chest radiotherapy (RTx), $\leq 40 \%$ of patients demonstrate changes on diagnostic imaging, while certain patients are asymptomatic $(2,3)$. The introduction of standardized lung dose volume constraints has led to a reduced incidence of radiation-induced pulmonary injuries, such as fibrosis and pulmonary insufficiency $(4,5)$; however, the two complications have not been completely eliminated $(6,7)$.

Irradiated lung tissues manifesting acute adverse reactions, such as RILT demonstrate enhanced production of inflammatory mediators (8). Therefore, the changes in cytokine concentrations during RTx may be predictive of lung toxicity and may, ultimately, lead to safer radiotherapy. Studies on biomarkers in lung cancer have been focused on the risk of developing lung cancer (9). Previous studies have demonstrated that assessments of cytokines, such as tumor growth factor- $\beta$ (TGF- $\beta 1$ ), interleukin-6 (IL-6) $(3,10)$, eotaxin, and monocyte chemoattractant protein-1 (8) have considerable clinical utility for predicting RILT and/or survival $(11,12)$. The majority of studies focused on biomarker levels prior to or following completion of RTx. Recent results suggest that serum concentrations of biomarkers from samples taken during the course of RTx may increase and correlate with exacerbation of RILT, thus enabling real-time risk assessment, prediction of fibrosis, and faster implementation of therapeutic interventions $(13,14)$.

\section{Materials and methods}

Patient recruitment. The current study was approved by the Bioethics Committee of the Medical University of Łódź (Łódź, 
Poland). All participants provided written informed consent for participation in the study. A total number of 26 patients (16 males and 10 females) who were treated between January, 2014 and July, 2015 for non-small cell lung cancer (NSCLC) clinical stages IIA-IIIB, according to the American Joint Committee on Cancer Staging Manual, 7th Edition (15) by sequential chemoradiotherapy or radiotherapy in a postsurgical setting following adjuvant chemotherapy were recruited for participation in this study. Blood samples $(5 \mathrm{ml})$ were taken from the participants at three time points during treatment for biomarker measurement, as follows: At baseline, prior to commencing radiotherapy; after a total of $20 \mathrm{~Gy}$; after a total of $40 \mathrm{~Gy}$. The samples after 20 and $40 \mathrm{~Gy}$ were collected just before the patient received the planned fraction. All blood samples were collected, stored in $4^{\circ} \mathrm{C}$ for clotting, then centrifuged at 1,500 x g (MPW-56; MPW Med Instruments, Warsaw, Poland) and stored at $-80^{\circ} \mathrm{C}$ until analysis.

Exclusion criteria. Patients were excluded according to the following criteria: Chronic cardiac insufficiency (class III/IV, according to the New York Heart Association classification system); severe renal insufficiency (stage IV, according to The Renal Association; glomerular filtration rate, $<30 \mathrm{ml} / 1.73 \mathrm{~m}^{2} / \mathrm{min}$ ); advanced stage of other pulmonary disease (chronic obstructive pulmonary disease stage IV according to the Global Initiative for Chronic Obstructive Lung Disease (16) classification or Asthma IV according to the Global Initiative for Asthma 2011 guidelines (17); or advanced liver insufficiency (Child-Pugh classification C and D). Patients that had been treated by stereotactic RTx and those with superior sulcus tumors or giant cell tumors were not included in the current study.

Recruitment scheme. Patients enrolled in the study underwent standard treatment according to National Comprehensive Cancer Network (NCCN) guidelines (18). Target volumes were delineated according to the International Commission of Radiation Units and Measurements Reports 62 and 83 (19). The total radiation doses delivered to clinical target volumes ranged between 54 and $74 \mathrm{~Gy}$, at photon energies of $6 \mathrm{MV}$, or a mix of 6 and $15 \mathrm{MV}$, using linear accelerators (Clinac ${ }^{\circledR} \mathrm{iX}$; Varian Medical Systems, Inc., Palo Alto, CA, USA). Treatment volume planning was performed based on three-dimensional conformal techniques, using computed tomography to delineate targets and organs at risk, and to plan the dose delivery. Dose-volume constraints for organs at risk were based on NCCN limitations. Every study patient was examined once weekly for pulmonary signs (a dry cough, fever and dyspnea) and symptoms suggestive of RILT. Healthy, age- and gender-matched participants were recruited $(n=26)$ for the control group.

Blood sample collection. Blood samples from the controls were assayed for cytokine levels and the results were compared with the baseline cytokine levels of the study patients. The following enzyme-linked immunosorbent assays were used to determine protein concentrations: Tumor necrosis factor- $\alpha$ (TNF- $\alpha$; DTA00C kit; R\&D Systems, Inc., Minneapolis, MN, USA), IL-6 (D6050 kit; R\&D Systems, Inc.), lipopolysaccharide-binding protein (LBP; KA0448 kit; Abnova (Taiwan) Corporation, Taipei, Taiwan), and C-reactive protein (CRP;
RD191006200R kit; BioVendor R\&D, Brno, Czech Republic), following the manufacturers' instructions.

Statistical analysis. Student's t-test was used to perform univariate comparisons of $\log _{10}$-transformed values. The Pearson product-moment correlation coefficients were determined to assess the strength of the linear relationship between two variables. Repeated-measures analysis of variance was used to evaluate temporal changes in cytokine levels. The sample size of the study was determined based on $80 \%$ statistical power for detecting effects equal to $\geq 66 \%$ of 1 standard deviation, with a predetermined type 1 error probability of 0.05 . An additional $10 \%$ of the calculated sample size of patients $(n=22)$ was recruited to account for missing data or technical errors, and an additional $10 \%$ for dropouts due to the increased risk of mortality during radiotherapy. $\mathrm{P}<0.05$ was considered to indicate a statistically significant difference.

\section{Results}

Basic statistics and matched-pair analysis. A total 26 patients (16 males and 10 females), with a mean age of $64.7 \pm 6.6$ years were included in the study cohort. The control group consisted of 17 males and 9 females, with a mean age of $61.3 \pm 5.3$ years. There were no differences in gender $(\mathrm{P}=1.00)$ and age $(\mathrm{P}=0.1031)$ between the patients with NSCLC and the control subjects. Table I demonstrates that at baseline, there were significant differences in three of the four cytokines between the patients with cancer and the control subjects. The only difference that was not significant was in the LBP values. This result indicates that LBP is not upregulated by the ongoing generalized inflammatory reaction against the tumor. During radiotherapy, none of the cytokine levels were significantly associated with the total dose administered at the time of cytokine assessment (Table I). At all time points, the IL-6, CRP, and TNF- $\alpha$ levels remained markedly above the control levels; the LBP levels remained stable and similar to the control level.

\section{Comparisons between dosimetric factors and serum cytokine} levels. Having established that the levels of inflammatory markers do not change significantly throughout radiotherapy, the correlation coefficients of their levels in association with the dosimetric parameters measured at the 40-Gy dose point were determined (Table II). The LBP level was significantly positively correlated with the mean lung radiation dose (MLD) ( $r=0.409 ; \mathrm{P}=0.038$; Fig. 1A) and there was borderline, but statistically insignificant correlation with V20 $(r=0.3536$; $\mathrm{P}=0.076$; Fig. 1B). The CRP level correlated positively with the MLD to the esophagus ( $r=0.404 ; \mathrm{P}=0.041$; Fig. $1 \mathrm{C})$. Only three study patients developed RILT more severe than grade 1 on the Radiation Therapy Oncology Group (RTOG) scale (20); therefore, assessments of inflammatory markers in association with RILT were not possible in the present study.

\section{Discussion}

The median LBP level was identified to be positively correlated with the radiation dose to the pulmonary tissue, which suggests 

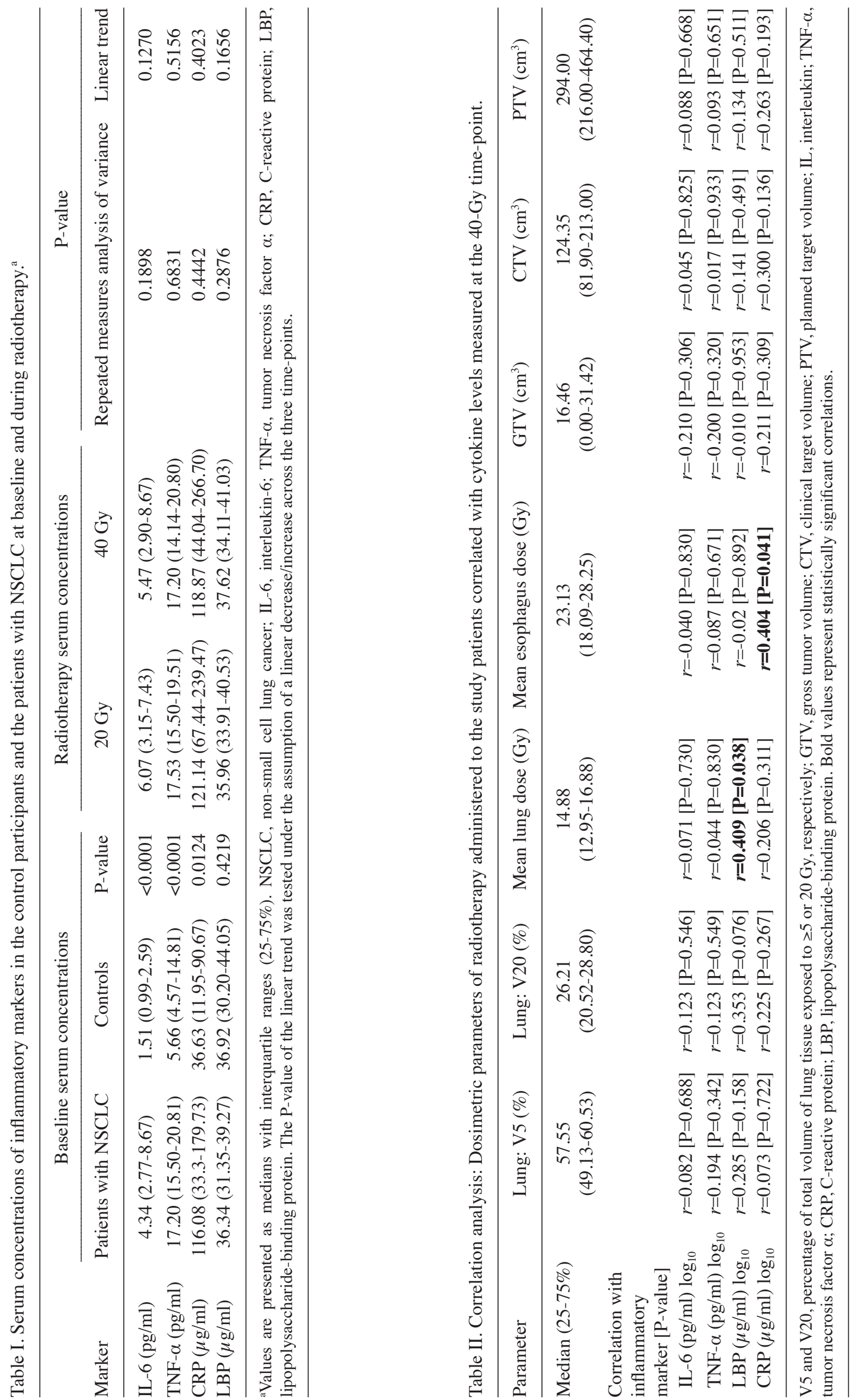


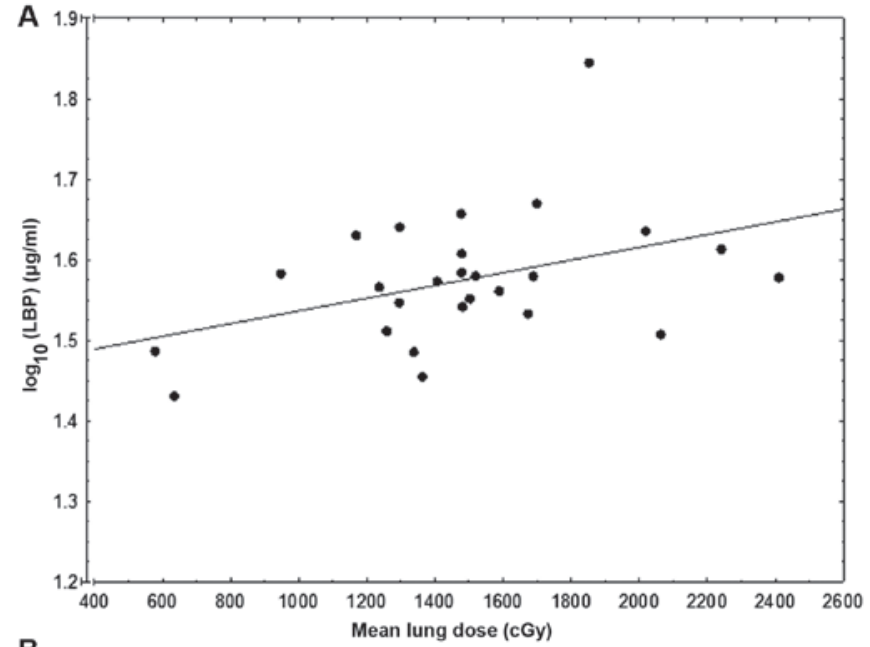

B

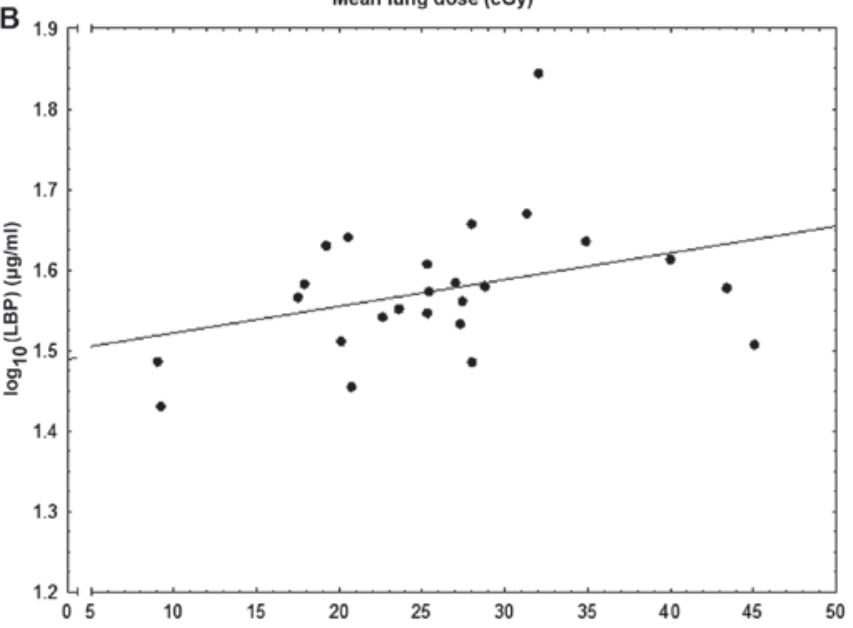

C

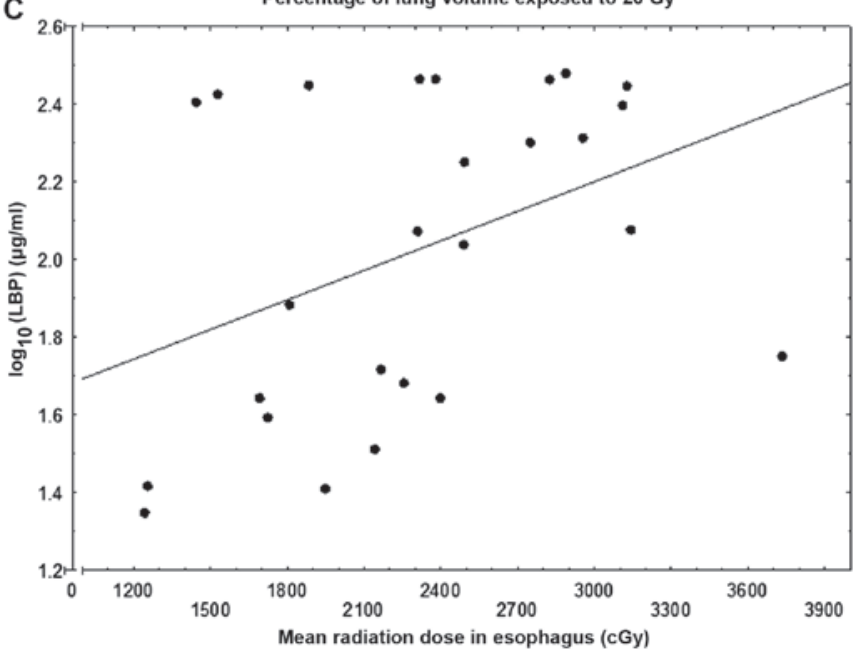

Figure 1. (A) Correlation between mean dose received by lung tissue and LBP levels. (B) Correlation between the \% volume of lung tissue exposed to $\geq 20$ Gy during chest radiotherapy and LBP levels. (C) Correlation between mean radiation dose received by the esophagus and CRP levels. LBP, lipopolysaccharide-binding protein.

that LBP assessments may warrant further investigations on radiotoxicity in NSCLC patients. An increased level of CRP seems to be associated with radiotoxicity to the esophagus, although cancer patients with elevated serum CRP levels prior to receiving radiotherapy hinder its utility for biodosimetry.

LBP belongs to the tubular lipid-binding protein family. It is produced by lung parenchyma, hepatocytes (21) and salivary glands (22). An increased LBP level was shown to be associated with worse outcomes of patients with infectious pneumonitis (23). In patients undergoing radiotherapy for NSCLC, the pretreatment levels of LBP were not correlated with outcome, although that study did not investigate the impact of RTx on LBP levels (12). However, in the current study serum LBP levels were observed to increase with V20 and MLD dosimetric parameters, although these parameters were well within the dose constraints described in the NCCN guidelines (16). This finding may be attributed to a localized inflammatory process in the lungs that may not be obvious, with radiation as the trigger. It is hypothesized that the increase in LBP is regulated via IL-6 secretion. However, as blood samples were collected just before the patient underwent the daily RTx fraction, the serum levels of IL-6 may have already dropped, accounting for measured IL- 6 concentrations that were not significantly increased (24).

The next stage of the current study, which will be conducted when the study cohort increases to a final size of 52 participants and when there is a 3-year follow-up, whether the serum level of LBP measured during RTx is correlated with clinical toxicity and late adverse effects will be evaluated. This analysis could not be performed in this pilot study as only a few patients presented with RILT during treatment.

Previous studies reported that the levels of IL-6 and TNF- $\alpha$ cytokines were correlated with RILT. The RTOG 91-03 study (10) reported finding these correlations after an acquired total dose of 10 or 20 Gy. IL- 6 was also found to be elevated before RTx and in patients with late manifestations of RILT (8). The predominant problem with IL-6 as a biomarker may be that it is a pleiotropic cytokine, which regulates many inflammatory processes, including induction of the acute phase reaction to injuries and infections. Therefore, IL-6 is a sensitive, but non-specific marker of the inflammatory process and potentially accounted for the significantly elevated pre-RTx levels of IL-6, as well as those of TNF- $\alpha$ and CRP in the study patients with NSCLC, compared to the control participants.

There were certain limitations of the present study. The patients enrolled in this study were eligible for either sequential chemoradiotherapy or adjuvant RTx. Although the current standard of radical treatment for locally advanced NSCLC is concurrent chemoradiotherapy (25), $60 \%$ of patients are deemed ineligible (26). The selection criteria of the present study may have led to bias, because the study patients were limited to those who underwent sequential chemotherapy or adjuvant RTx. However, as a result of our selection criteria, the effects of chemotherapy on the early inflammatory response were avoided. The absence of a temporal trend in LBP levels during $\mathrm{RTx}(\mathrm{P}=0.167)$ suggest that the significant correlation of LBP with MLD was not due to disease progression or the initial disease stage, but rather was associated with the actual radiation dose delivered to pulmonary tissue in a specific volume.

In conclusion, the present study found that LBP levels are associated with the radiation dose delivered to the pulmonary tissue and may have the potential to be markers of RILT. A larger study group and longer follow-up time are required to establish whether the observed differences have clinical implications. 


\section{Acknowledgements}

The present study was funded by the National Science Center (grant no. 2012/05/N/NZ5/02621) and the INTER program of the FNP (grant no. 127/UD/SKILLS/2015).

\section{References}

1. Garipagaoglu M, Munley MT, Hollis D, Poulson JM, Bentel GC, Sibley G, Anscher MS, Fan M, Jaszczak RJ, Coleman RE, et al: The effect of patient-specific factors on radiation-induced regional lung injury. Int J Radiat Oncol Biol Phys 45: 331-338, 1999.

2. Claude L, Pérol D, Ginestet C, Falchero L, Arpin D, Vincent M, Martel I, Hominal S, Cordier JF and Carrie C: A prospective study on radiation pneumonitis following conformal radiation therapy in non-small-cell lung cancer: Clinical and dosimetric factors analysis. Radiother Oncol 71: 175-181, 2004.

3. Kong FM, Ao X, Wang L and Lawrence TS: The use of blood biomarkers to predict radiation lung toxicity: A potential strategy to individualize thoracic radiation therapy. Cancer Control 15 : 140-150, 2008

4. Abratt RP and Morgan GW: Lung toxicity following chest irradiation in patients with lung cancer. Lung Cancer 35: 103-109, 2002.

5. Marks LB, Bentzen SM, Deasy JO, Kong FM, Bradley JD, Vogelius IS, El Naqa I, Hubbs JL, Lebesque JV, Timmerman RD, et al: Radiation dose-volume effects in the lung. Int J Radiat Oncol Biol Phys 76 (Suppl): S70-S76, 2010.

6. Rubin P, Finkelstein J and Shapiro D: Molecular biology mechanisms in the radiation induction of pulmonary injury syndromes: Interrelationship between the alveolar macrophage and the septal fibroblast. Int J Radiat Oncol Biol Phys 24: 93-101, 1992.

7. Morgan GW and Breit SN: Radiation and the lung: A reevaluation of the mechanisms mediating pulmonary injury. Int J Radiat Oncol Biol Phys 31: 361-369, 1995.

8. Siva S, MacManus M, Kron T, Best N, Smith J, Lobachevsky P, Ball D and Martin O: A pattern of early radiation-induced inflammatory cytokine expression is associated with lung toxicity in patients with non-small cell lung cancer. PLoS One 9: e109560, 2014.

9. Chaturvedi AK, Caporaso NE, Katki HA, Wong HL, Chatterjee N, Pine SR, Chanock SJ, Goedert JJ and Engels EA: C-reactive protein and risk of lung cancer. J Clin Oncol 28 : 2719-2726, 2010

10. Hartsell WF, Scott CB, Dundas GS, Mohiuddin M, Meredith RF, Rubin P and Weigensberg IJ: Can serum markers be used to predict acute and late toxicity in patients with lung cancer? Analysis of RTOG 91-03. Am J Clin Oncol 30: 368-376, 2007.

11. Dehing-Oberije C, Aerts H, Yu S, De Ruysscher D, Menheere P, Hilvo M, van der Weide H, Rao B and Lambin P: Development and validation of a prognostic model using blood biomarker information for prediction of survival of non-small-cell lung cancer patients treated with combined chemotherapy and radiation or radiotherapy alone (NCT00181519, NCT00573040, and NCT00572325). Int J Radiat Oncol Biol Phys 81: 360-368, 2011.

12. Walker MJ, Zhou C, Backen A, Pernemalm M, Williamson AJ, Priest LJ, Koh P, Faivre-Finn C, Blackhall FH, Dive C, et al: Discovery and validation of predictive biomarkers of survival for non-small cell lung cancer patients undergoing radical radiotherapy: Two proteins with predictive value. EBioMedicine 2: 841-850, 2015.
13. Chen Y, Williams J, Ding I, Hernady E, Liu W, Smudzin T, Finkelstein JN, Rubin P and Okunieff P: Radiation pneumonitis and early circulatory cytokine markers. Semin Radiat Oncol 12 (Suppl 1): 26-33, 2002.

14. Mazeron R, Etienne-Mastroianni B, Pérol D, Arpin D, Vincent M, Falchero L, Martel-Lafay I, Carrie C and Claude L: Predictive factors of late radiation fibrosis: A prospective study in non-small cell lung cancer. Int J Radiat Oncol Biol Phys 77: 38-43, 2010.

15. Wrona A and Jassem J: The new TNM classification in lung cancer. Pneumonol Alergol Pol 78: 407-417, 2010 (In Polish).

16. Soriano JB, Lamprecht B, Ramírez AS, Martinez-Camblor P, Kaiser B, Alfageme I, Almagro P, Casanova C, Esteban C, Soler-Cataluña JJ, et al: Mortality prediction in chronic obstructive pulmonary disease comparing the GOLD 2007 and 2011 staging systems: A pooled analysis of individual patient data. Lancet Respir Med 3: 443-450, 2015.

17. Miedinger D, Neukomm E, Chhajed PN, Schnyder A, Naef M, Ackermann $\mathrm{M}$ and Leuppi JD: The use of the Asthma Control Test in general practice and its correlation with asthma control according to the GINA guidelines. Curr Med Res Opin 27: 2301-2308, 2011

18. National Comprehensive Cancer Network (NCCN): NCCN Guidelines ${ }^{\circledR}$. NCCN, Fort Washington, PA, USA, 2015.

19. No authors listed: Prescribing, recording, and reporting photon-beam intensity-modulated radiation therapy (IMRT): Contents. J ICRU 10: NP, 2010.

20. Faria SL, Aslani M, Tafazoli FS, Souhami L and Freeman CR: The challenge of scoring radiation-induced lung toxicity. Clin Oncol (R Coll Radiol) 21: 371-375, 2009.

21. Wolk K, Witte E, Hoffmann U, Doecke WD, Endesfelder S, Asadullah K, Sterry W, Volk HD, Wittig BM and Sabat R: IL-22 induces lipopolysaccharide-binding protein in hepatocytes: A potential systemic role of IL-22 in Crohn's disease. J Immunol 178: 5973-5981, 2007.

22. Abdolhosseini M, Sotsky JB, Shelar AP, Joyce PB and Gorr SU: Human parotid secretory protein is a lipopolysaccharide-binding protein: Identification of an anti-inflammatory peptide domain. Mol Cell Biochem 359: 1-8, 2012.

23. Villar J, Pérez-Méndez L, Espinosa E, Flores C, Blanco J, Muriel A, Basaldúa S, Muros M, Blanch L, Artigas A, et al; GRECIA and GEN-SEP Groups: Serum lipopolysaccharide binding protein levels predict severity of lung injury and mortality in patients with severe sepsis. PLoS One 4: e6818, 2009.

24. Dentener MA, Vreugdenhil AC, Hoet PH, Vernooy JH, Nieman FH, Heumann D, Janssen YM, Buurman WA and Wouters EF: Production of the acute-phase protein lipopolysaccharide-binding protein by respiratory type II epithelial cells: Implications for local defense to bacterial endotoxins. Am J Respir Cell Mol Biol 23: 146-153, 2000

25. Aupérin A, Le Péchoux C, Rolland E, Curran WJ, Furuse K, Fournel P, Belderbos J, Clamon G, Ulutin HC, Paulus R, et al: Meta-analysis of concomitant versus sequential radiochemotherapy in locally advanced non-small-cell lung cancer. J Clin Oncol 28: 2181-2190, 2010.

26. De Ruysscher D, Botterweck A, Dirx M, Pijls-Johannesma M, Wanders R, Hochstenbag M, Dingemans AM, Bootsma G, Geraedts W, Simons J, et al: Eligibility for concurrent chemotherapy and radiotherapy of locally advanced lung cancer patients: A prospective, population-based study. Ann Oncol 20: 98-102, 2009. 